\title{
Viral infection overcomes ineffectiveness of anti-tumoral CD8+ $T$ cell mediated cytotoxicity
}

Fan Zhou ${ }^{1}$, Justa Kardash ${ }^{1}$, Hilal Bhat ${ }^{1}$, Vikas Duhan ${ }^{1}$, Sarah-Kim Friedrich ${ }^{1}$, Judith Bezgovsek ${ }^{1}$, Halime Kalkavan ${ }^{2}$, Michael Bergerhausen ${ }^{1}$, Max Schiller ${ }^{1}$, Yara Machlah ${ }^{1}$, Tim Brandenburg ${ }^{1}$, Cornelia Hardt ${ }^{1}$, Michal Krolik ${ }^{3}$, Lukas Flatz ${ }^{3,4}$, Philipp A. Lang ${ }^{3 *}$, and Karl S. Lang ${ }^{1 *}$

1. Institute of Immunology, Medical Faculty, University of Duisburg-Essen, Hufelandstrasse 55, Essen 45147, Germany

2. Department of Immunology, St. Jude Children's Research Hospital, 262 Danny Thomas Place, Memphis, TN 38105-3678, USA

3. Departement Biozentrum, Experimental Virology, University of Basel, Klingelbergstrasse 70, Basel 4056, Switzerland

4. Institute of Immunobiology, Kantonsspital St.Gallen, Rorschacher Strasse 95, St.Gallen, Switzerland

5. Institute of Molecular Medicine, Heinrich-Heine-University, Moorenstrasse 5, Düsseldorf 40225, Germany

*Co-senior author

Address correspondence to karlsebastian.lang@uk-essen.de

Key words: Cancer, Melanoma, T cell response, virotherapy, tumor immunology 


\section{Abstract}

With the integration of PD-1 and CTLA-4 targeting immune checkpoint blockade into cancer treatment regimes, the anti-tumoral cytotoxicity of tumor-specific $\mathrm{CD} 8^{+} \mathrm{T}$ cells is well established. However, while the unresponsiveness of $\mathrm{CD} 8^{+} \mathrm{T}$ cells against big tumors is mainly explained by $\mathrm{T}$ cell exhaustion, other factors contributing to $\mathrm{CD} 8^{+} \mathrm{T}$ cell failure remain not well studied. Here we used a mouse melanoma model to study the interaction of growing tumor cells, innate immunity and $\mathrm{CD} 8^{+} \mathrm{T}$ cell responses induced by viral replication. Mouse model of melanoma (B16F10-OVA) and infections with arenaviruses. Growing B16F10-OVA cells did not induce systemic ablation of tumor specific $\mathrm{CD}^{+} \mathrm{T}$ cells. However, despite the presence of tumor-infiltrating $\mathrm{CD} 8^{+} \mathrm{T}$ cells, the anti-tumoral immune response was very limited. T cell anergy against the tumor was accompanied with a strong down-regulation of MHC-I on advanced tumors. LCMV infection restored the MHC class I expression, enhanced $\mathrm{T}$ cell function and lead to tumor regression. This study shows that tumor progression does not necessary lead to systemic exhaustion of the anti-tumoral $\mathrm{CD} 8^{+} \mathrm{T}$ cell response. Lack of innate signals is an additional reason for limited $\mathrm{CD} 8^{+} \mathrm{T}$ cell mediated cytotoxicity against the tumor. 


\section{Introduction}

Cancer development is strongly linked to accumulation of mutations that cause expression of high amount of tumor-specific and tumor-associated antigens. Such antigens could lead to the activation of an anti-tumoral immune responses, which might mediate control of the tumor growth[1-5]. Advanced neoplasms acquire several properties to escape from the host's immune system leading to invasion of the tumor. Immune evasion mechanisms include dysregulation of the antigen presentation pathways, exhaustion of $\mathrm{T}$ cells, release of negative regulatory signals and recruitment of immunosuppressive cells to the tumor microenvironment supporting the establishment of the immune tolerance to cancer cells[6-11]. The immunogenic tolerance to tumors limits the effects of the anticancer chemotherapy and irradiation[12-14]. Therefore new approaches in anti-tumor therapy are needed to overcome the tumor immune escape.

Many human cancers contain infiltrating immune cells. In particular cytotoxic $\mathrm{CD}^{+} \mathrm{T}$ cells belong to the tumor microenvironment and play a key role in tumor eradication[4, 15-17]. Antigen-presenting cells (APCs) provide tumor-associated antigens to the cytotoxic T cells, leading to priming of such $\mathrm{T}$ cells $[18,19]$. In fact, previous studies demonstrated that APCs, which are located in the lymph node (LN) internalize and cross-present tumor-associated antigens to cytotoxic CD8 ${ }^{+} \mathrm{T}$ cells[1, 20-22]. Beside the APCs, malignant cells are also able to trigger activation of cytotoxic $\mathrm{T}$ cells[23]. Presentation of tumor-specific neoantigens as well as tumor-associated antigens occur by MHC class I molecules expressed on the surface of tumor cells enabling cytotoxic $\mathrm{T}$ cells to recognize the antigen[23, 24]. In response to the detection of foreign antigens, cytotoxic T cells attack and destroy the MHC-I positive malignant cells. However, tumors use different escape mechanism to bypass the immunosurveillance by cytotoxic T cells. Loss or downregulation of MHC-I is a frequent mechanism allowing the neoplasms to evade identification by cytotoxic T cells[4, 23]. MHC-I downregulation was observed in a variety of malignancies revealing an association with progression or recurrence of disease, overall survival and increase in metastasis[25-27]. In particular, in tumors derived from epithelia, MHC-I molecules were reduced in more than $75 \%$ of patients[28]. Decrease of the MHC-I expression in tumors is a result of structural alterations in genes encoding MHC-I heavy chain, $\beta$ microglobulin or components of the antigen processing machinery[23, 29].

Viruses are well known to stimulate the innate and adaptive immune system. Recently, viral therapy has emerged as a promising approach to fight cancer. Cancer cells are a good target for non-oncolytic viruses which replicate selectively and activate immune defenses against tumor cells without harming normal tissue[30, 31]. In mouse models, previous research showed that acute infections with WE strain of lymphocytic choriomeningitis virus (LCMV-WE) exert antitumor effects[9, 32, 33]. Beside 
these principal inflammatory stimuli, LCMV can be used as a vaccine vector to immunize against tumor antigens[34-37].

The current research aimed to investigate the effect of viral infection with LCMV and Candid\#1 on tumor-specific $\mathrm{CD}^{+} \mathrm{T}$ cells using a murine melanoma model.

\section{Materials and Methods}

Mice: C57BL6J (CD45.2 $)$ and OT-1 were maintained on the C57BL/6 background. (back crossed as many as 16 times) and were bred as homozygotes. For adoptive transfer experiments mice, congenic for C57BL/6 (CD45.1) were used to distinguish between transferred cells (CD45.2) and endogenous (CD45.1) cells. The spontaneous tumor models B16F10-OVA (Melanoma) were used on C57BL/6 background. All animals were housed in single ventilated cages. Six- to eight-week-old, age and sex matched mice were used for all the experiments performed. All animals were housed in single ventilated cages. Animal experiments were authorized by the Nordrhein Westfalen Landesamt für Natur, Umwelt und Verbraucherschutz (Recklinghausen, Germany) and in accordance with the German law for animal protection or according to institutional guidelines at the Ontario Cancer Institute of the University Health Network and at McGill University.

Viruses: The LCMV strain WE was originally obtained from F. Lehmann-Grube (Heinrich Pette Institute, Hamburg, Germany) and was propagated on L929 cells, MC57 cells, or both. LCMV-OVA was from Lukas Flatz (Department of Dermatology/Allergology,St. Gallen,Switzerland). Candid\#1 was grown in Vero E6 cells derived from P. Cannon (Department of Molecular Microbiology and Immunology, University of Southern California, Los Angeles).

Tumor induction: The C57BL/6-drived melanoma cell line B16F10-OVA-transfected clone was maintained at $37^{\circ} \mathrm{C}$ with $5 \% \mathrm{CO} 2$ in DMEM medium supplemented with $10 \%$ heat-in-activated fetal calf serum, penicillin, streptomycin and Glutamine. $1 \times 10^{6}$ B16F10-OVA cells were injected subcutaneously in $200 \mathrm{ul}$ Medium on the left flank. Tumor size was determined by the formula $\mathrm{L} \times \mathrm{W} \times \mathrm{W}$ where $\mathrm{L}=$ length, $\mathrm{W}=$ width, on the indicated days.

In vivo killer assay: 24 hours after B16-OVA injected subcutaneously to LCMV-OVA immunized mice, splenocytes differentially labeled with 20 or 200nM CFSE and load with or without $100 \mathrm{nM}$ ovalbumin $257-264$ peptide, respectively. The cells were collected $24 \mathrm{hr}$ after i.v and s.c. injection. Splenocytes, which were not labeled with peptide served as negative control for determine the specific lysis. 
Flow cytometry: Tetramers were provided by the National Institutes of Health (NIH) Tetramer Facility. Cells were stained with allophycocyanin (APC)-labeled ovalbumin(SIINFEKL) MHC class I tetramer (TCMetrix) for 15 minutes at $37^{\circ} \mathrm{C}$. After incubation, the samples were stained with anti-CD8 (53-6.7) (eBioscience) for 30 minutes at $4^{\circ} \mathrm{C}$. Absolute numbers of ovaspecific CD8+ T cells were calculated from FACS analysis using fluorescing beads (BD Biosciences). All stained cells were analysed on an LSRII or a FACSFortessa (BD Biosciences) flow cytometer, and data were analysed with Flowjo software.

Intracellular cytokine staining (ICS): For ICS, Cells were stimulated with 100ng/ml PMA (Sigma) and $50 \mathrm{ng} / \mathrm{ml}$ ionomycin (Sigma-Aldrich) at $37^{\circ} \mathrm{C}$ for $3 \mathrm{hr}$ in the presence of Brefeldin A $(10 \mu \mathrm{g} / \mathrm{ml}$; Sigma) to allow accumulation of intracellular cytokines. After staining of surface maker CD8, cells were fixed and permeabilized, followed by stain of IFN- $\gamma$ (XMG 1.1).

\section{Histological analysis and Immunocytochemistry: Histological analysis were} performed on snap-frozen tissue as previously described[30]. In brief, sections were fixed with acetone for $10 \mathrm{~min}$, and non-specific antigens were blocked in phosphate-buffered saline (PBS) containing $2 \%$ FCS for $15 \mathrm{~min}$, followed by various stainings for $45 \mathrm{~min}$.

Immunocytochemistry was performed on cells grown on cover-slips[31]. In brief, cells were fixed in 4\% Formalin/PBS for $10 \mathrm{~min}$, washed in PBS and then permeabilized in 1\% TritonX-PBS for $10 \mathrm{~min}$. After blocking with 10\% FCS/PBS for 30-60 min, various stainings for 45 min were followed. Cover slips were mounted on microscope slides using mounting medium (S3023, Dako).

Images were acquired with a fluorescence microscope (KEYENCE BZ II analyzer). Quantifications were performed using the Image $\mathbf{J}$ software (NIH).

Statistical analysis: Graphs were compiled and statistical analyses were performed with Graphpad Prism software. Data are expressed as means \pm SEM. Student's t-test was used to detect statistically significant differences between groups. Significant differences between several groups were detected by one-way analysis of variance (ANOVA) with Bonferroni or Dunnett post hoc tests. The level of statistical significance was set at $\mathrm{P}<0.05$.

\section{Results}

\section{Systemic expansion of tumor-specific CD8 $+T$ cells despite growing tumors}


To determine the influence of locally growing tumors on antigen specific $\mathrm{CD} 8^{+} \mathrm{T}$ cells, we treated C57BL/6 mice with B16F10-OVA cells subcutaneously. Within a week subcutaneous melanomas were palpable. At that time point, we intravenously injected mice with a single cycle LCMV-vector carrying the ovalbumin antigen. In the absence of growing tumors, immunization with LCMV-OVA led to fast expansion of OVA-specific $\mathrm{CD} 8^{+} \mathrm{T}$ cells (Fig. 1A). Interestingly, presence of growing tumors accelerated the expansion of OVA-specific CD8 ${ }^{+} \mathrm{T}$ cells (Fig. 1A), while treatment without LCMV-OVA did not lead to measurable OVA-specific $\mathrm{CD} 8^{+} \mathrm{T}$ cell responses. Next, we wondered whether the increased number of OVA-specific $\mathrm{CD}^{+} \mathrm{T}$ cells could impact on the tumor growth. To this end, we compared growth of B16F10-OVA tumors in mice combined with and without LCMVOVA application. Surprisingly LCMV-OVA treatment did not affect tumor growth (Fig. 1B).

\section{Presence of growing tumors did not influence CD8+ $T$ cell function}

Next we aimed to analyze whether the localization and/or function of OVA-specific $\mathrm{CD}^{+} \mathrm{T}$ cells could explain unaffected tumor growth in LCMV-OVA treated mice. Therefore, we performed tetramer staining of $\mathrm{T}$ cells isolated from spleen, tumor-draining lymph nodes and tumors 10 days after LCMV-OVA immunization. Frequencies of Tet-OVA ${ }^{+} \mathrm{CD} 8^{+} \mathrm{T}$ cells were significantly increased in spleens and lymph nodes of mice, which had received subcutaneous B16-OVA melanomas in addition to LCMV-OVA (Fig. 2A). In line IFN-gamma production of $\mathrm{T}$ cells from secondary lymphoid organs after in vitro restimulation was enhanced in B16-OVA bearing mice, which were immunized with LCMV-OVA (Fig. 2B). These data further supported that presence of B16-OVA tumors rather enhanced the anti-tumor immune response than suppressing it. From these data it remains unclear, why tumors still grow in the presence of tumor-specific $\mathrm{CD} 8^{+} \mathrm{T}$ cells.

\section{Tumor-specific CD8+ $T$ cells show normal cytotoxic function in vivo}

Next, we wondered whether the systemic and local cytotoxicity is influenced by growing tumors. Therefore we infected mice with LCMV-OVA and then on day 7 injected B16-OVA cells subcutaneously. 24 hours later the amount of injected tumor cells within the injection area were quantified. LCMV-OVA pretreated mice reduced the number of subcutaneously detectable tumor cells (Fig. 3A). This confirmed the anti-tumoral capacity of OVA-specific $\mathrm{CD}^{+} \mathrm{T}$ in immunized mice. Next we analyzed whether the presence of B16-OVA tumor cells reduces the cytotoxicity of OVAspecific $\mathrm{CD}^{+} \mathrm{T}$ cells. Therefore we treated mice with LCMV-OVA. One group of mice received additionally B16-OVA cells. Cytotoxicity was analyzed after 24 hours by injecting CFSE labeled peptide loaded splenocytes. Presence of B16-OVA cells did not influence specific lysis of OVAloaded splenocytes within the draining lymph node (Fig. 3B). However, presence of B16-OVA cells accelerated cytotoxicity of OVA-specific $\mathrm{CD} 8^{+} \mathrm{T}$ cells within the injection site (Fig. 3B). Next we 
asked whether bigger tumors similarly accelerate local CD8 T cell responses. To do so, C57BL/6 mice were treated with B16F10-OVA cells subcutaneously on day 0 . Mice were immunized with $2 \times 10^{5}$ PFU of LCMV-OVA on day 7 and in vivo cytotoxicity was determined eight days later. Circulating OVA-specific $\mathrm{T}$ cells from mice harboring growing subcutaneus melanomas showed enhanced cytotoxicity in blood when compared to control animals (Fig. 3C). Together these data suggest, that in our model, growing tumors rather enhanced the frequencies and cytotoxic activity of tumor-specific $\mathrm{CD}^{+} \mathrm{T}$ cells than limiting it.

\section{Growing melanomas down-modulate MHC-I in vivo}

So far, our data suggests increased anti-tumoral activity of systemic CD8 ${ }^{+} \mathrm{T}$ cells in LCMV-OVA immunized mice. However, established subcutaneous tumors progressed despite the activation of cytotoxic immune defenses. We wondered, if the intratumoral antigen-presentation was altered and thus responsible for the lacking effects of cytotoxic $\mathrm{T}$ cells on the progression of tumors. To get insights, we performed immunofluorescence of tumor cells or tumors from B16F10-tumors bearing C57BL/6 mice. Indeed, advancing tumors showed limited MHC-I expression compared to tumor cells in culture (Fig. 4).

\section{Innate activation by Candid\#1 restored MHC-I expression, activated tumor specific CD8+ $\mathbf{T}$ cells and limited tumor growth.}

We postulated that lack of inflammatory signals within the tumor led to limited MHC-I expression. Indeed, infection of tumors with the replicating arenavirus strains LCMV or Candid\#1 increased expression of MHC-I in B16 tumors (Fig. 5A). In line with these findings naïve tumor-specific CD8 ${ }^{+}$ $\mathrm{T}$ cells proliferated and expanded upon LCMV infection $($ Fig.5B+C). Moreover, virus infection led to an increase of tumor-infiltrating $\mathrm{CD} 8^{+} \mathrm{T}$ cells (Fig. 5D). Since, replication-proficient viruses induce a strong innate immune response that cooperates with adaptive immune defenses, we reasoned, that additional infection with a proliferative, non-cytoloytic arenaviruses might reverse the $\mathrm{T}$ cell anergy that we observed in our vaccination model with the single-cycle LCMV-OVA virus. To this end, we again treated C57BL/6 mice with B16F10-OVA cells. One group of mice was treated with LCMVOVA. Another group was treated with LCMV-OVA and additionally treated with Candid\#1. Indeed, Candid \#1 treated mice led to significant delay in tumor progression (Fig. 5E).

\section{Discussion}

Our studies focused on the functionality of cytotoxic $\mathrm{T}$ cells in a murine melanoma model with B16F10-OVA. We found that vaccination induced expansion and activation of cytotoxic $\mathrm{T}$ cells was strongly enhanced when mice where harboring OVA-antigen expressing cancers. However, adaptive immune activation could not prevent or delay progression of established tumors, despite tumor- 
infiltration. Strikingly, ex vivo restimulation of OVA-specific cytotoxic T cells proved their functionality. Yet, intratumoral cytotoxic $\mathrm{T}$ cells remained unresponsive at late stages of tumor. We show that this T cell anergy is associated with low expression level of MHC class I on tumor cells. Furthermore, replicating non-oncolytic arenaviruses like LCMV and Junín virus vaccine, Candid\#1 reverse the expression of MHC class I and lead to suppressed tumor growth.

Several types of tumors are characterized by a strong infiltration of cytotoxic T cells reflecting a preexisting host immunity directed against cancer cells[38]. However, under the circumstances of chronic inflammation, the tumor infiltrating cytotoxic T-cells lose their functionality and undergo exhaustion[4, 39, 40]. Many immunosuppressive factors secreted by tumor cells as well as by immune cells from the tumor microenvironment, such as IL-10, iNOS, ROS or TGF- $\beta$ are implicated in the cytotoxic $\mathrm{T}$ cell dysfunction[41, 42]. PD1- receptor inhibits the reactivity of the cytotoxic $\mathrm{T}$ cells converting them to an exhausted phenotype[43, 44]. Consequently, drugs blocking the PD-1 or the PD-L1 restore the anti-tumor activity of the cytotoxic $\mathrm{T}$ cells resulting in reduction of tumor growth and clinical benefit in a vast array of tumors of different origin[38, 45-47]. Especially, in the late stage of cancer development PD-1 expression the tumor cells increase causing tumor progression and metastasis due to PD-1 mediated cytotoxic T cell exhaustion[38]. Accordingly, we also saw tumorspecific $\mathrm{CD}^{+} \mathrm{T}$ cells infiltrating into advanced melanoma but being anergic to the cancer cells. We assume, that the unresponsiveness of the $\mathrm{CD} 8^{+} \mathrm{T}$ cells to the tumor might be mainly attributed to the downregulation of the MHC class I molecules on the surface of tumor cells. In the late phase, established tumors display less MHC-I on their surface due to the alterations of the components of antigen presentation pathway over time making the malignant cells invisible for the cytotoxic $\mathrm{T}$ cells and resulting in immune escape[4, 23]. Nevertheless, reduction of MHC-I expression is a reversible state. Type I and type II interferon signaling contribute to the upregulation of MHC-I on tumor cells[28, 48-50]. In our previous studies[9] we showed that replicating arenaviruses induce a strong interferon response via the activation of the innate immune response. Therefore, we reasoned that arenavirus infection can reverse $\mathrm{T}$ cell anergy towards tumor cells via modulation of antigenpresentation. Indeed, our data show an upregulation of MHC I upon viral infection that is accompanied with increased $\mathrm{T}$ cell activation in tumors, resulting in suppression of tumor growth.

However, the modulation of the tumor microenvironment and immune-responses within caused by replicating non-oncolytic viruses are very complex. Our study focuses on $\mathrm{CD} 8^{+} \mathrm{T}$ cell activation and observations on MHCI presentation in virus-treated or -untreated tumors. Additional factors to consider, are wide-ranging effects of Interferon signaling induced by viral replication and by activated $\mathrm{T}$ cells. These include direct cytotoxic effects of interferons, their impact on tumor-angiogenesis and immunomodulatory effects (REF). Other immune cell types e.g. like dendritic cells, regulatory $\mathrm{T}$ cells $\mathrm{CD}^{+} \mathrm{T}$ cells might probably contribute to viral infection induced immunomodulation to reverse anergy of cytotoxic $\mathrm{T}$ cell and remain subject for future studies. 
B16F10-OVA cells activated cytotoxic $\mathrm{CD} 8^{+} \mathrm{T}$ cells. The low amounts of $\mathrm{CD} 8^{+} \mathrm{T}$ cells infiltrating in tumor and the low expression level of MHC class I on tumor surface might explain the failure of cytotoxic $\mathrm{T}$ cells regulating the tumor growth. Using an experimental model of melanoma, our results revealed that accumulation and activation of intratumoral $\mathrm{CD}^{+} \mathrm{T}$ effector cells was enhanced by LCMV infection, suggesting that the limited infiltration of $\mathrm{CD}^{+} \mathrm{T}$ cells observed in B16F10-OVA melanoma recovered by LCMV. We have previously shown that LCMV can replicate in many tumor models[9], which strongly support that LCMV and Junín virus vaccine, Candid\#1 reversed the MHC class I expression. We discovered that LCMV treatment promoted the proliferation of $\mathrm{CD}^{+} \mathrm{T}$ cells in draining LNs, and LCMV combined PD-1 cocktail significantly reduced tumor growth compared to LCMV treatment alone (data not show). To better understand antitumor immunity, it is very important to explore how LCMV, might be other non-oncolytic arenavirus in the future, affect the function and proliferation of $\mathrm{CD} 8^{+} \mathrm{T}$ cell. Therefore, it would be of great interest to examine the ability of LCMV to induced $\mathrm{CD} 8^{+} \mathrm{T}$ cells function.

In summary, replicating arenaviruses LCMV and Junín virus vaccine, Candid\#1 can reserve MHC class I expression in established tumors to overcome $\mathrm{T}$ cell anergy. This virus-induced functional immunomodulation might serve as a potential therapeutic strategy for cancer treatment. 


\section{References:}

1. Asano K, Nabeyama A, Miyake Y, Qiu CH, Kurita A, Tomura M, et al. CD169positive macrophages dominate antitumor immunity by crosspresenting dead cellassociated antigens. Immunity. 2011;34(1):85-95. Epub 2011/01/05. doi: 10.1016/j.immuni.2010.12.011. PubMed PMID: 21194983.

2. Gajewski TF, Schreiber H, Fu YX. Innate and adaptive immune cells in the tumor microenvironment. Nat Immunol. 2013;14(10):1014-22. Epub 2013/09/21. doi: 10.1038/ni.2703. PubMed PMID: 24048123; PubMed Central PMCID: PMCPMC4118725. 3. Vinay DS, Ryan EP, Pawelec G, Talib WH, Stagg J, Elkord E, et al., editors. Immune evasion in cancer: Mechanistic basis and therapeutic strategies. Seminars in cancer biology; 2015: Elsevier.

4. Shalapour S, Karin MJTJoci. Immunity, inflammation, and cancer: an eternal fight between good and evil. 2015;125(9):3347-55.

5. Schumacher TN, Schreiber RDJS. Neoantigens in cancer immunotherapy. 2015;348(6230):69-74.

6. Melief CJ. Cancer immunotherapy by dendritic cells. Immunity. 2008;29(3):37283. Epub 2008/09/19. doi: 10.1016/j.immuni.2008.08.004. PubMed PMID: 18799145.

7. Sica A, Bronte VJTJoci. Altered macrophage differentiation and immune dysfunction in tumor development. 2007;117(5):1155-66.

8. Gabrilovich D. Mechanisms and functional significance of tumour-induced dendritic-cell defects. Nat Rev Immunol. 2004;4(12):941-52. Epub 2004/12/02. doi: 10.1038/nri1498. PubMed PMID: 15573129.

9. Kalkavan H, Sharma P, Kasper S, Helfrich I, Pandyra AA, Gassa A, et al. Spatiotemporally restricted arenavirus replication induces immune surveillance and type I interferon-dependent tumour regression. 2017;8:14447.

10. Kitamura T, Qian B-Z, Pollard JWJNRI. Immune cell promotion of metastasis. 2015;15(2):73.

11. Gajewski TF, Woo S-R, Zha Y, Spaapen R, Zheng Y, Corrales L, et al. Cancer immunotherapy strategies based on overcoming barriers within the tumor microenvironment. 2013;25(2):268-76.

12. Zeh HJ, Downs-Canner S, McCart JA, Guo ZS, Rao UN, Ramalingam L, et al. First-inman study of western reserve strain oncolytic vaccinia virus: safety, systemic spread, and antitumor activity. Molecular Therapy. 2015;23(1):202-14.

13. Zapata J, Salvato MJV. Arenavirus variations due to host-specific adaptation. 2013;5(1):241-78.

14. Tsai KK, Zarzoso I, Daud AI. PD-1 and PD-L1 antibodies for melanoma. Human vaccines \& immunotherapeutics. 2014;10(11):3111-6.

15. Galon J, Angell HK, Bedognetti D, Marincola FMJI. The continuum of cancer immunosurveillance: prognostic, predictive, and mechan istic signatures. 2013;39(1):1126.

16. Jiang Y, Li Y, Zhu B. T-cell exhaustion in the tumor microenvironment. Cell Death Dis. 2015;6(6):e1792. Epub 2015/06/19. doi: 10.1038/cddis.2015.162. PubMed PMID: 26086965; PubMed Central PMCID: PMCPMC4669840.

17. Ochsenbein AF, Sierro S, Odermatt B, Pericin M, Karrer U, Hermans J, et al. Roles of tumour localization, second signals and cross priming in cytotoxic T-cell induction. 2001;411(6841):1058. 
18. Roberts EW, Broz ML, Binnewies M, Headley MB, Nelson AE, Wolf DM, et al. Critical role for CD103+/CD141+ dendritic cells bearing CCR7 for tumor antigen trafficking and priming of T cell immunity in melanoma. 2016;30(2):324-36.

19. McDonnell AM, Robinson BW, Currie AJJC, Immunology D. Tumor antigen crosspresentation and the dendritic cell: where it all begins? 2010;2010.

20. Nierkens S, Tel J, Janssen E, Adema GJJTii. Antigen cross-presentation by dendritic cell subsets: one general or all sergeants? 2013;34(8):361-70.

21. Semmrich M, Plantinga M, Svensson-Frej M, Uronen-Hansson H, Gustafsson T, Mowat A, et al. Directed antigen targeting in vivo identifies a role for CD103+ dendritic cells in both tolerogenic and immunogenic T-cell responses. 2012;5(2):150.

22. Fehres CM, Unger WW, Garcia-Vallejo JJ, van Kooyk YJFii. Understanding the biology of antigen cross-presentation for the design of vaccines against cancer. 2014;5:149.

23. Reeves E, James EJI. Antigen processing and immune regulation in the response to tumours. 2017;150(1):16-24.

24. Teng MW, Galon J, Fridman W-H, Smyth MJJTJoci. From mice to humans: developments in cancer immunoediting. 2015;125(9):3338-46.

25. Meissner M, Reichert TE, Kunkel M, Gooding W, Whiteside TL, Ferrone S, et al. Defects in the human leukocyte antigen class I antigen processing machinery in head and neck squamous cell carcinoma: association with clinical outcome. 2005;11(7):255260 .

26. Mehta AM, Jordanova ES, Kenter GG, Ferrone S, Fleuren G-JJCI, Immunotherapy. Association of antigen processing machinery and HLA class I defects with clinicopathological outcome in cervical carcinoma. 2008;57(2):197-206.

27. Kaneko K, Ishigami S, Kijima Y, Funasako Y, Hirata M, Okumura H, et al. Clinical implication of HLA class I expression in breast cancer. 2011;11(1):454.

28. Garrido F, Ruiz-Cabello F, Aptsiauri NJCI, Immunotherapy. Rejection versus escape: the tumor MHC dilemma. 2017;66(2):259-71.

29. Leone P, Shin E-C, Perosa F, Vacca A, Dammacco F, Racanelli VJJotNCI. MHC class I antigen processing and presenting machinery: organization, function, and defects in tumor cells. 2013;105(16):1172-87.

30. Kottke T, Errington F, Pulido J, Galivo F, Thompson J, Wongthida P, et al. Broad antigenic coverage induced by viral cDNA library-based vaccination cures established tumors. 2011;17(7):854.

31. Joshi MD, Unger WJ, Storm G, van Kooyk Y, Mastrobattista EJJoCR. Targeting tumor antigens to dendritic cells using particulate carriers. 2012;161(1):25-37.

32. Hermans IF, Daish A, Moroni-Rawson P, Ronchese FJCI, Immunotherapy. Tumorpeptide-pulsed dendritic cells isolated from spleen or cultured in vitro from bone marrow precursors can provide protection against tumor challenge. 1997;44(6):341-7.

33. Chambers CA, Kuhns MS, Egen JG, Allison JPJAroi. CTLA-4-mediated inhibition in regulation of $\mathrm{T}$ cell responses: mechanisms and manipulation in tumor immunotherapy. 2001;19(1):565-94.

34. Flatz L, Hegazy AN, Bergthaler A, Verschoor A, Claus C, Fernandez M, et al. Development of replication-defective lymphocytic choriomeningitis virus vectors for the induction of potent CD8+ T cell immunity. 2010;16(3):339.

35. Morales-Kastresana A, Catalán E, Hervás-Stubbs S, Palazón A, Azpilikueta A, Bolaños E, et al. Essential complicity of perforin-granzyme and FAS-L mechanisms to achieve tumor rejection following treatment with anti-CD137 mAb. 2013;1(1):3.

36. Prévost - Blondel A, Neuenhahn M, Rawiel M, Pircher HJEjoi. Differential requirement of perforin and IFN - $\gamma$ in CD8 T cell - mediated immune responses against B16. F10 melanoma cells expressing a viral antigen. 2000;30(9):2507-15. 
37. Ragonnaud E, Andersson A-MC, Pedersen AE, Laursen H, Holst PJJV. An adenoviral cancer vaccine co-encoding a tumor associated antigen together with secreted 4-1BBL leads to delayed tumor progression. 2016;34(18):2147-56.

38. Smahel M. PD-1/PD-L1 Blockade Therapy for Tumors with Downregulated MHC Class I Expression. Int J Mol Sci. 2017;18(6):1331. Epub 2017/06/22. doi: 10.3390/ijms18061331. PubMed PMID: 28635644; PubMed Central PMCID: PMCPMC5486151.

39. Chaudhary B, Elkord EJV. Regulatory T cells in the tumor microenvironment and cancer progression: role and therapeutic targeting. 2016;4(3):28.

40. Thommen DS, Schumacher TNJCC. T cell dysfunction in cancer. 2018;33(4):547-

62.

41. Baitsch L, Baumgaertner P, Devêvre E, Raghav SK, Legat A, Barba L, et al. Exhaustion of tumor-specific CD8 $+\mathrm{T}$ cells in metastases from melanoma patients. 2011;121(6):2350-60.

42. $\mathrm{Ng} \mathrm{CT}$, Oldstone MB. IL-10: achieving balance during persistent viral infection. Interleukin-10 in Health and Disease: Springer; 2014. p. 129-44.

43. Chikuma S. Basics of PD-1 in self-tolerance, infection, and cancer immunity. Int J Clin Oncol. 2016;21(3):448-55. Epub 2016/02/13. doi: 10.1007/s10147-016-0958-0. PubMed PMID: 26864303.

44. Zhou Q, Munger M, Highfill SJB. Program death-1 (PD-1) signaling and regulatory $\mathrm{T}$ cells (Tregs) collaborate to resist the function of adoptively transferred cytotoxic $\mathrm{T}$ lymphocytes (CTLs) in advanced acute myeloid leukemia (AML). 6:22.

45. Iwai $Y$, Ishida M, Tanaka Y, Okazaki T, Honjo T, Minato NJPotNAoS. Involvement of PD-L1 on tumor cells in the escape from host immune system and tumor immunotherapy by PD-L1 blockade. 2002;99(19):12293-7.

46. Ma W, Gilligan BM, Yuan J, Li TJJoh, oncology. Current status and perspectives in translational biomarker research for PD-1/PD-L1 immune checkpoint blockade therapy. 2016;9(1):47.

47. Tumeh PC, Harview CL, Yearley JH, Shintaku IP, Taylor EJ, Robert L, et al. PD-1 blockade induces responses by inhibiting adaptive immune resistance. 2014;515(7528):568.

48. Jongsma ML, Guarda G, Spaapen RMJMi. The regulatory network behind MHC class I expression. 2017.

49. Palmer K, Harries M, Gore M, Collins MJC, immunology EIC. Interferon - alpha (IFN - $\alpha$ ) stimulates anti - melanoma cytotoxic $\mathrm{T}$ lymphocyte (CTL) generation in mixed lymphocyte tumour cultures (MLTC). 2000;119(3):412-8.

50. Yang I, Kremen TJ, Giovannone AJ, Paik E, Odesa SK, Prins RM, et al. Modulation of major histocompatibility complex Class I molecules and major histocompatibility complex-bound immunogenic peptides induced by interferon- $\alpha$ and interferon- $\gamma$ treatment of human glioblastoma multiforme. 2004;100(2):310-9. 


\section{Figure Legends:}

Figure 1: Systemic expansion of tumor-specific CD8+ T cells despite growing tumors

C57BL/6 mice were treated with $1 \times 10^{6}$ B16F10-OVA cells subcutaneously on day 0 . Mice were immunized with $2 \times 10^{5}$ PFU of LCMV-OVA on day 7 . A: Tumor growth was analyzed $(n=4)$. B: Frequencies of Tet-OVA ${ }^{+} \mathrm{CD}^{+} \mathrm{T}$ cells were analyzed in the blood $(\mathrm{n}=4)$.

\section{Figure 2: Presence of growing tumors do not influence CD8+ T cell function}

C57BL/6 mice were treated with $1 \times 10^{6}$ B16F10-OVA cells subcutaneously on day 0 . Mice were immunized with $2 \times 10^{5}$ PFU of LCMV-OVA on day 7. A: Frequencies of Tet-OVA ${ }^{+} \mathrm{CD}^{+} \mathrm{T}$ cells were analyzed in spleen, tumor draining lymph Node and tumor on day $17(n=4)$. B: Frequencies of IFN-gamma producing $\mathrm{CD} 8^{+} \mathrm{T}$ cells were analyzed in spleen and tumor draining lymph Node after in vitro restimulation on day $17(\mathrm{n}=4)$.

\section{Figure 3: Local tumor-specific CD8+ $T$ cells are cytotoxic}

A: C57BL/6 mice were treated without (Control) or with 2×105 PFU LCMV-OVA on day 0. On day 7 mice were treated with $1 \times 106$ B16F10-OVA cells subcutaneously. Number of B16F10-OVA cells in the subcutaneous injection area was analyzed on day $8(n=4)$. B: C57BL/6 mice were treated without (Control) or with $2 \times 10^{5}$ PFU LCMV-OVA on day 0. On day 7 B16F10-OVA cells were injected subcutaneously. In vivo cytotoxicity was analyzed 24 hours later $(n=4)$. C: C57BL/6 mice were treated with $1 \times 10^{6}$ B16F10-OVA cells subcutaneously on day 0 . Mice were immunized with $2 \times 10^{5}$ PFU of LCMV-OVA on day 7. In vivo cytotoxicity was analyzed on day 15 in blood and the tumor $(n=4)$.

\section{Figure 4: Growing melanoma cells down-modulate MHC-I}

Immunofluorescence of tumor cells or tumors from B16F10-tumors bearing C57BL/6 mice $(n=4)$. Scale bar, $200 \mu \mathrm{m}$.

Figure 5: Innate activation by Candid\#1 restored MHC-I expression, activated tumor specific CD8+ $T$ cells and limited tumor growth 
A: C57BL/6 mice were treated with B16F10-OVA cells on day 0. Mice were treated with LCMV or Candid\#1 and day 7 and MHC-I expression was determined on day $20(n=4)$. Scale bar, $200 \mu \mathrm{m}$. BD: CD45.1 mice were treated with B16F10-OVA cells on day 0. On day 7 CFSE-labeled OT-1 cells (CD45.2) were injected intravenously and mice were infected with LCMV on day 8. Proliferation of OT-1 cells in the draining LNs was analyzed on day 13 by CFSE dilution later $(\mathbf{B}, \mathrm{n}=4)$. Total number of tumor-specific $\mathrm{CD} 8^{+} \mathrm{T}$ cells was determined in the draining lymph node $(\mathbf{C}, \mathrm{n}=4)$. Infiltration of tumor-specific $\mathrm{CD} 8^{+} \mathrm{T}$ cells was determined by Immunofluorescence $(\mathbf{D}, \mathrm{n}=4)$. $\mathbf{E}$ : C57BL/6 mice were treated with B16F10-OVA cells on day 0. Mice were treated with LCMV or Candid\#1 and day 7 and tumor growth was monitored. 


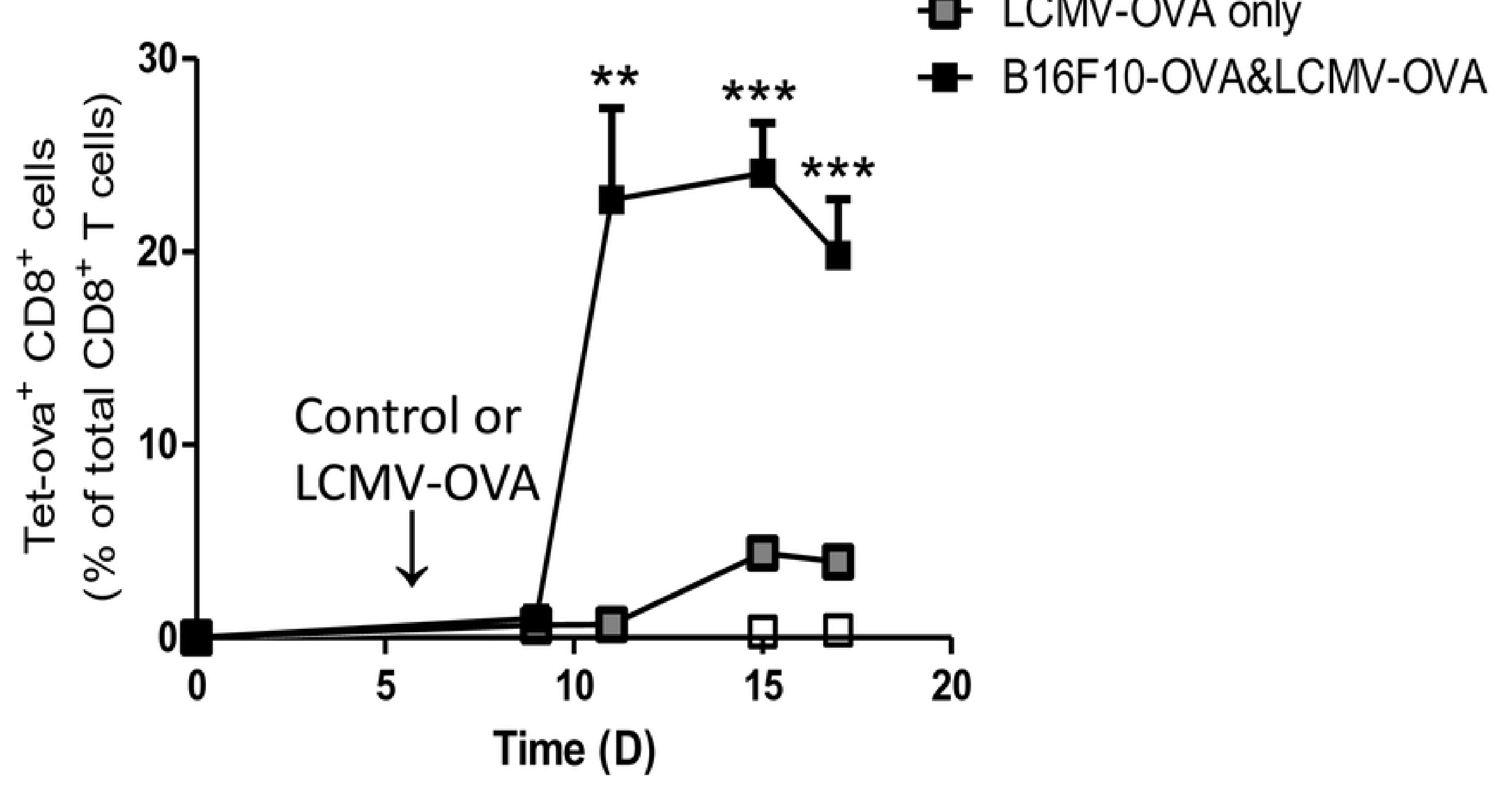

․ B16F10-OVA only

ㅁ. LCMV-OVA only 
마 B16F10-OVA only

- - LCMV-OVA only

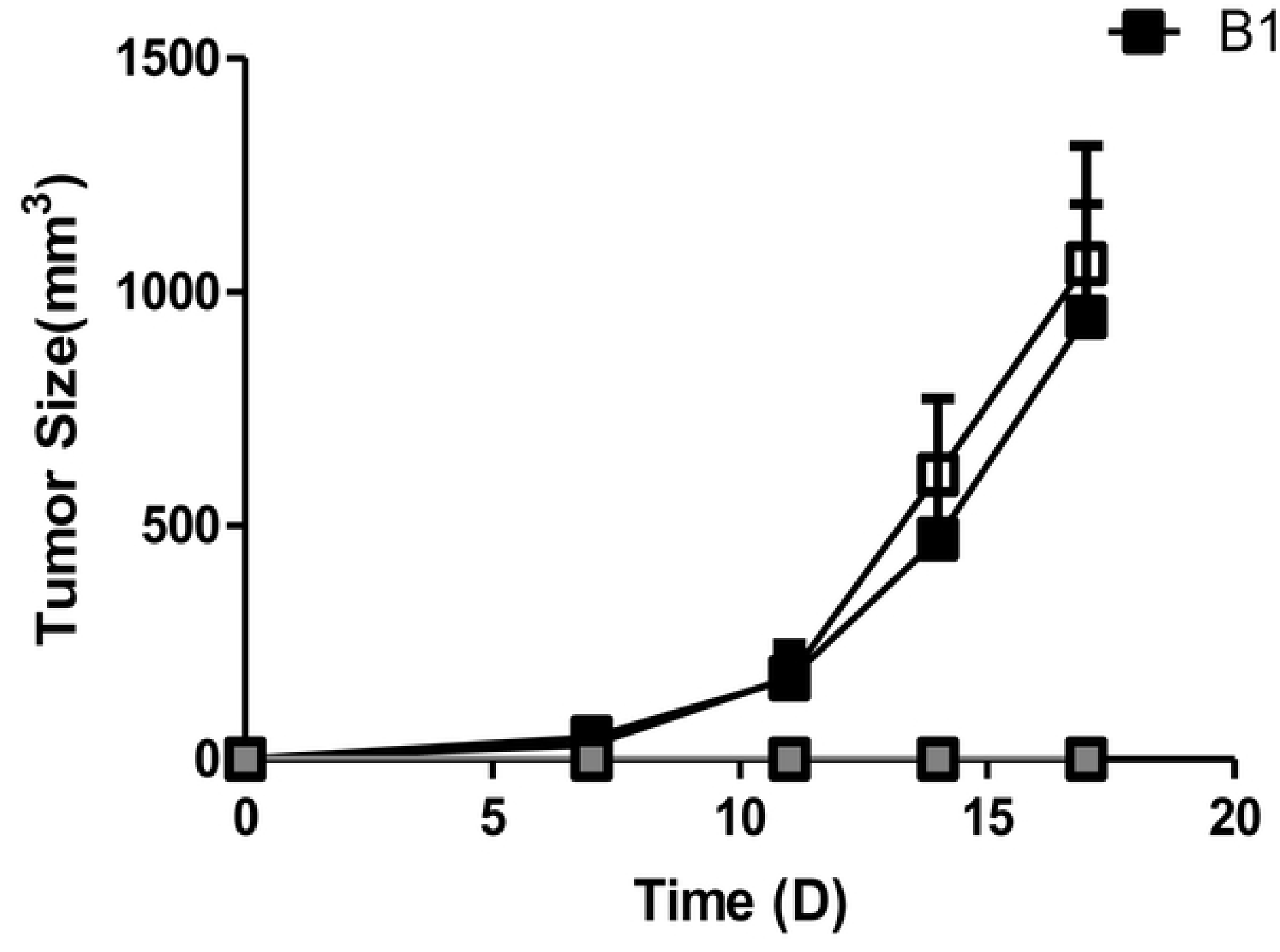

Figure1B 
Spleen

Tumor
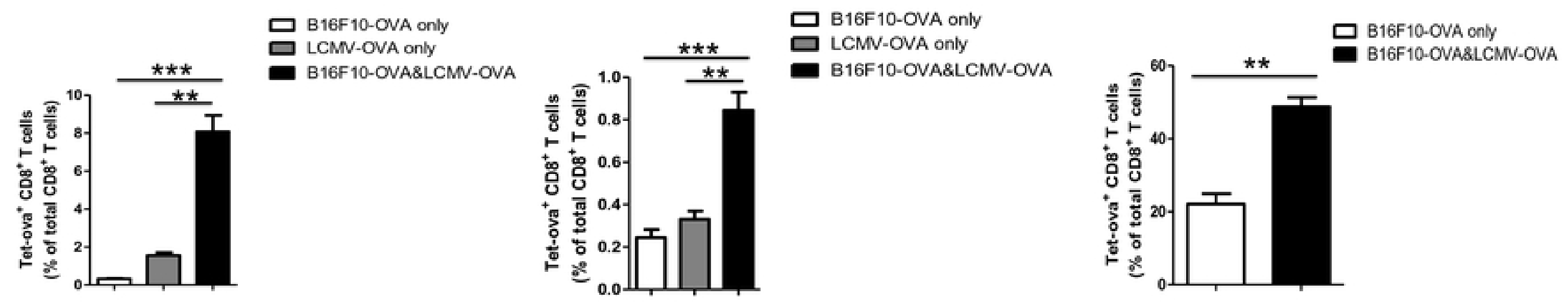

Figure2A 


\section{Spleen}

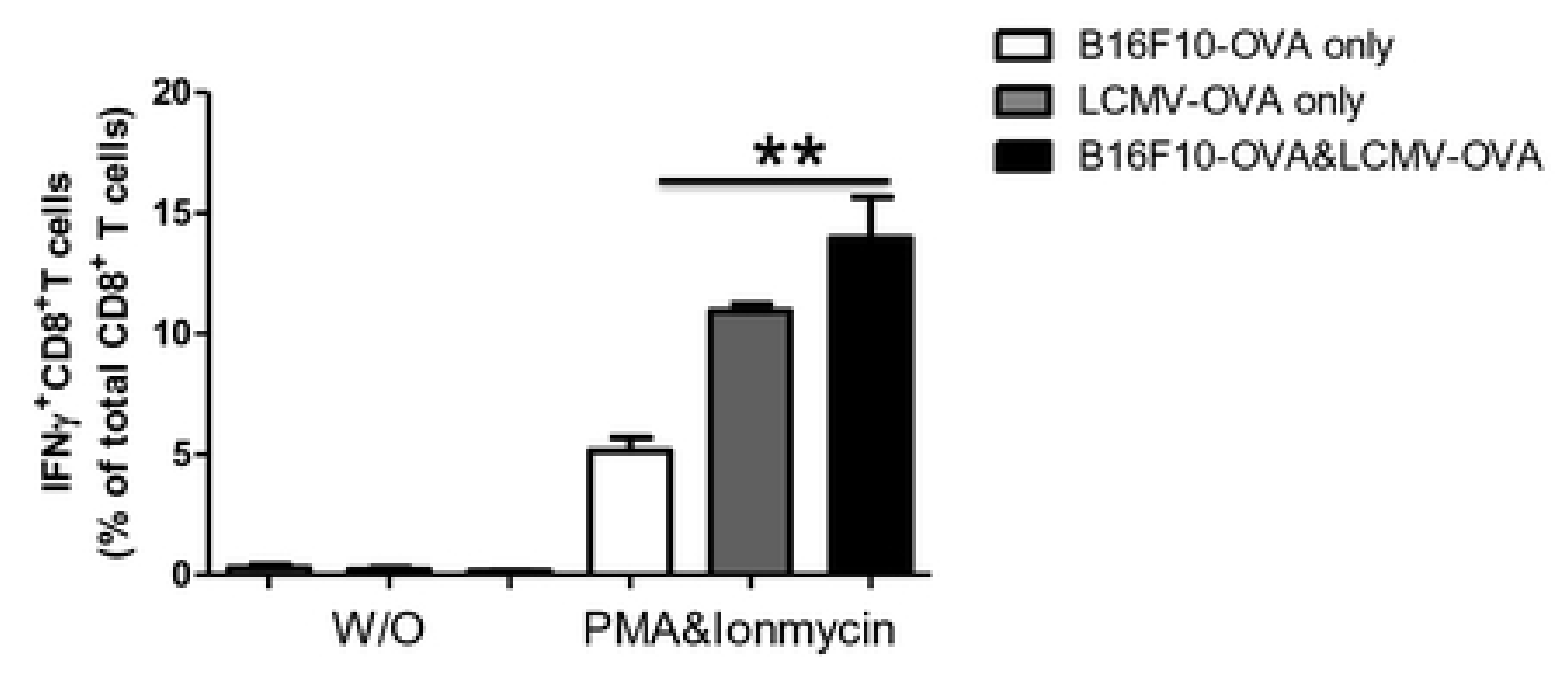

\section{TdLN}

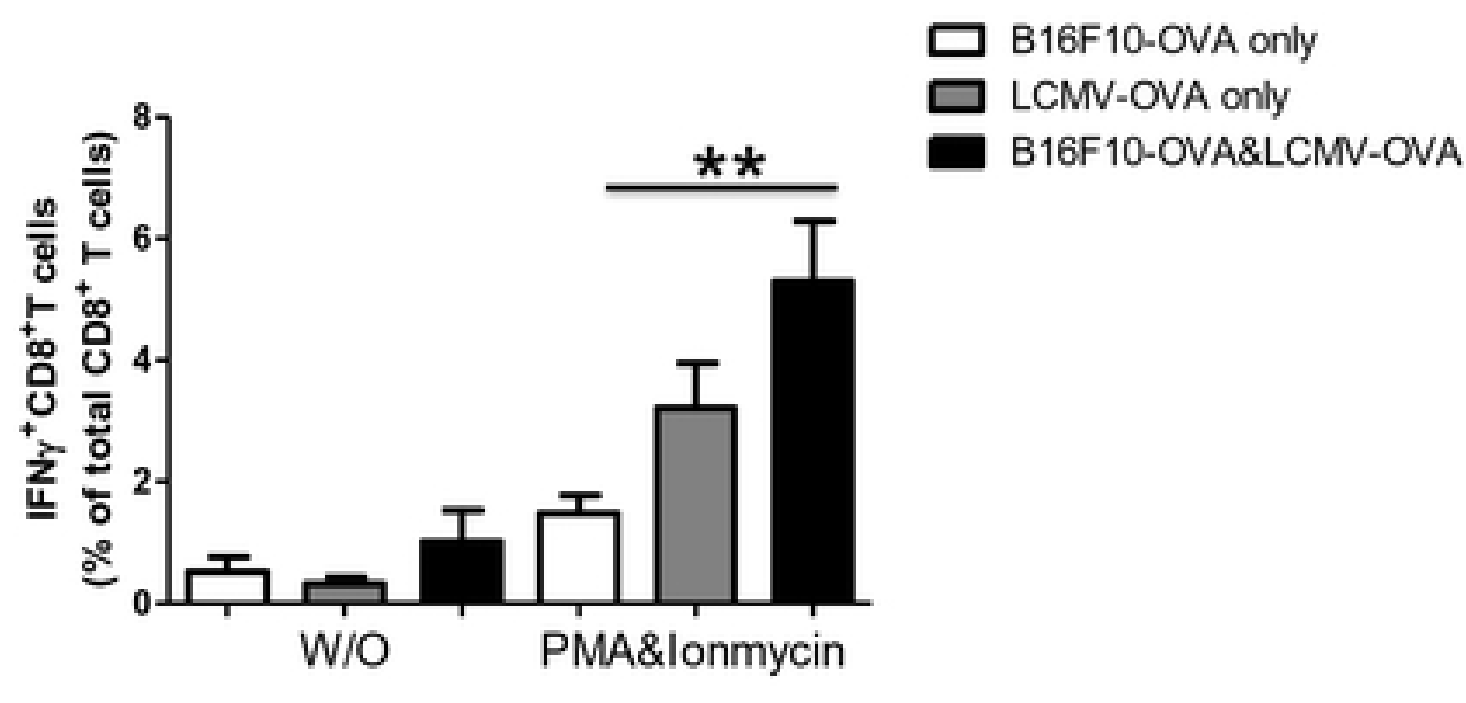

Figure2B 


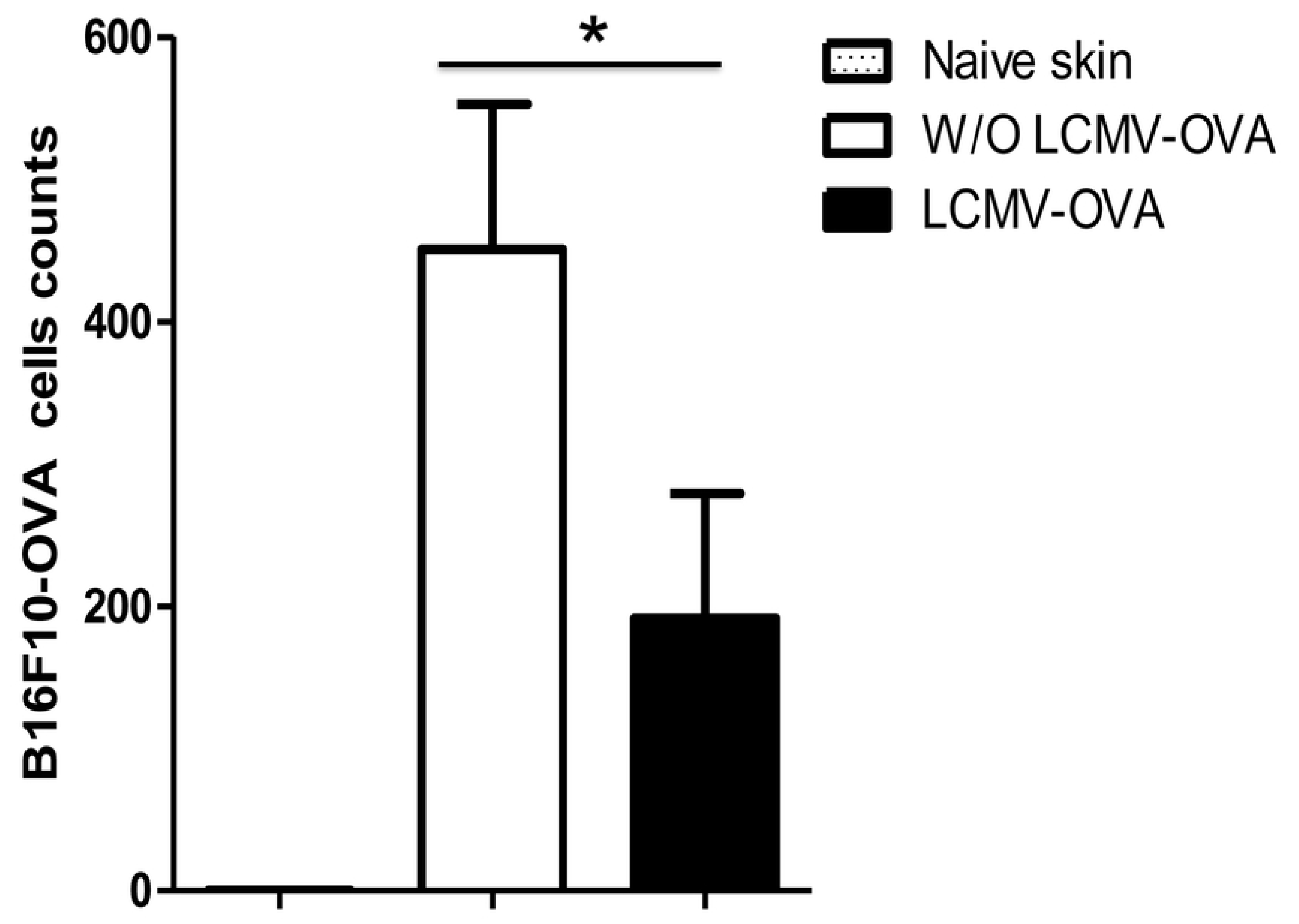

Figure $3 \mathrm{~A}$ 


\section{Lymph node}

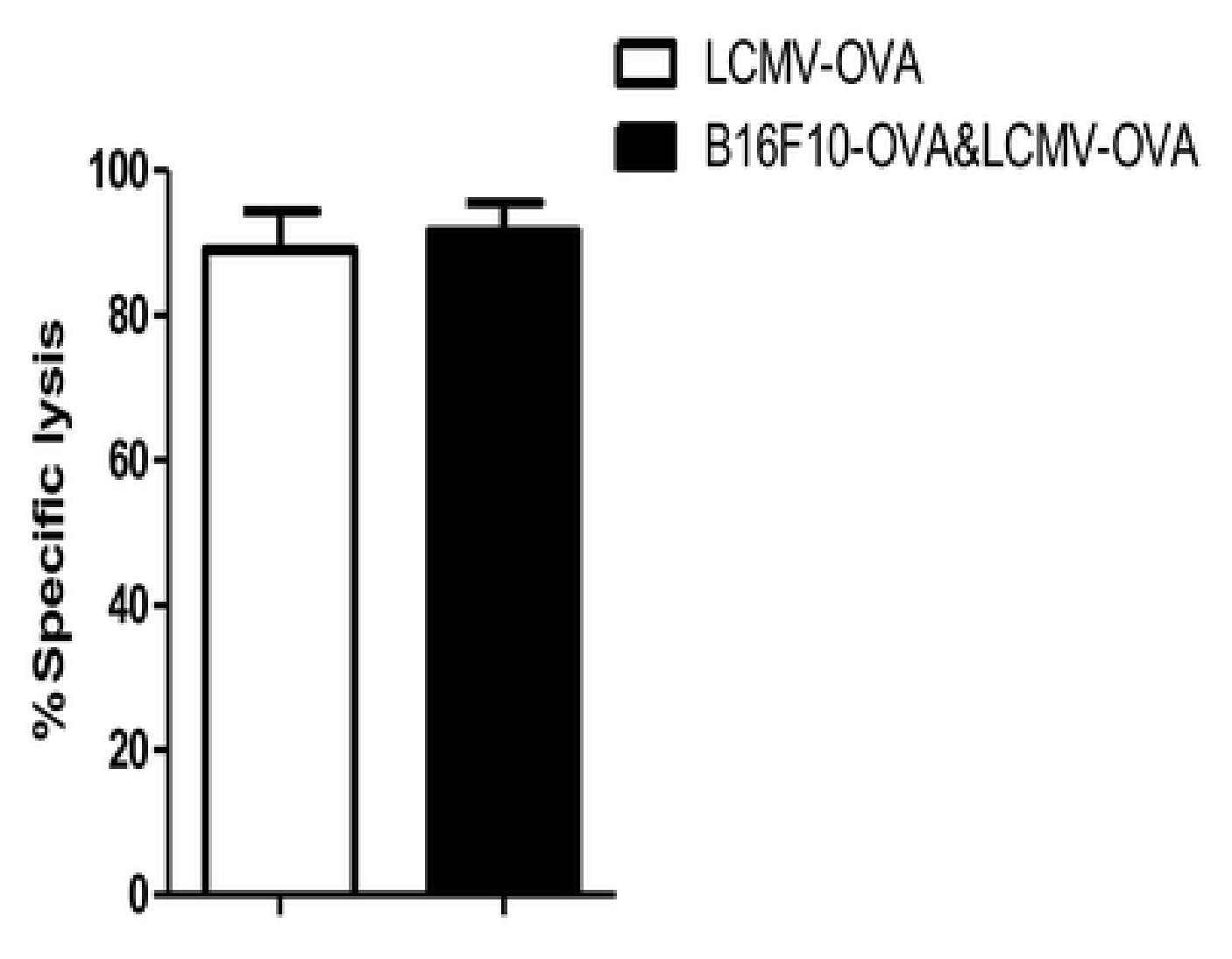

\section{Injection site}

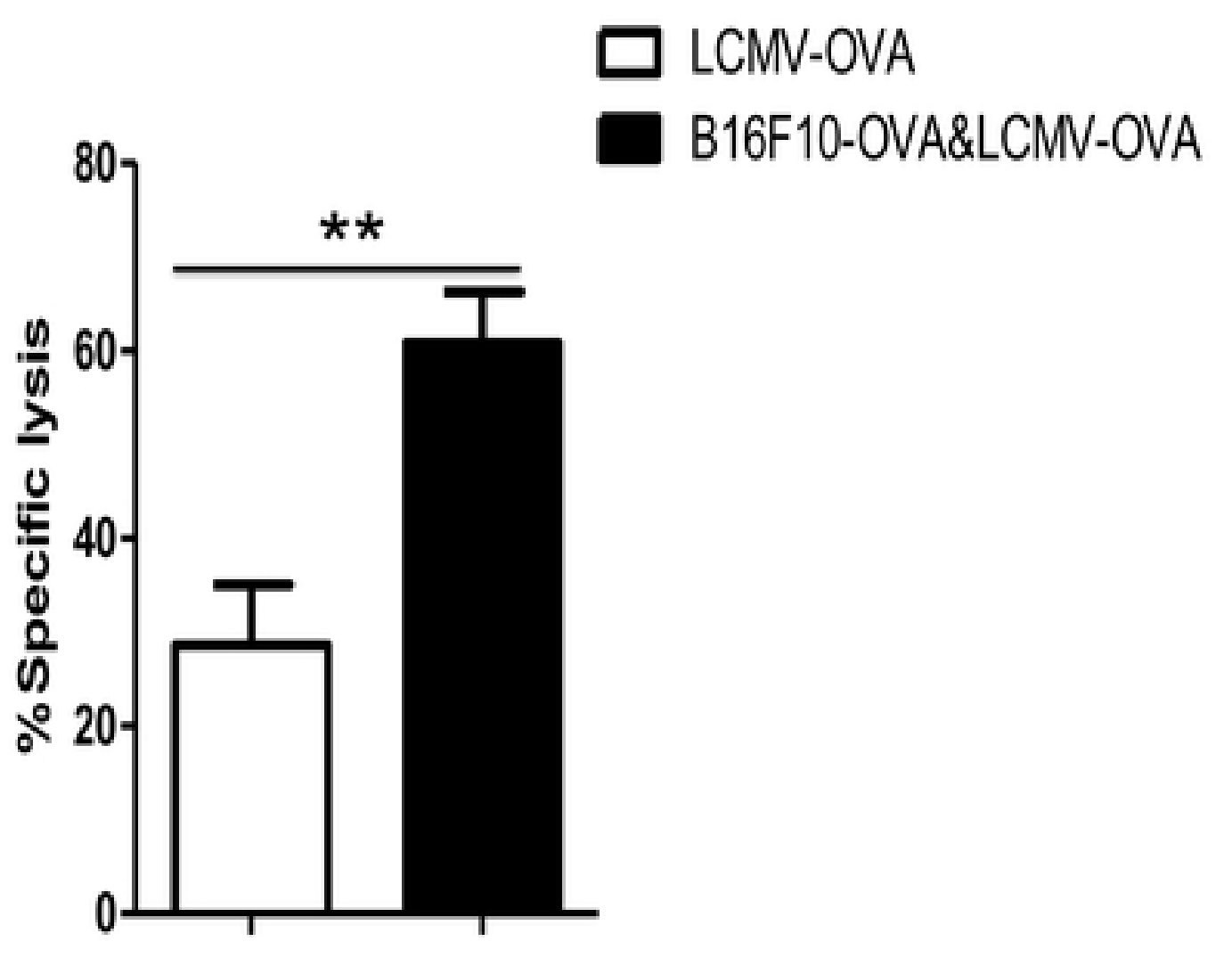

Figure3B 


\section{Blood}

$\square$ LCMV-OVA

$\square$ LCMV-OVA\&B16 s.C.

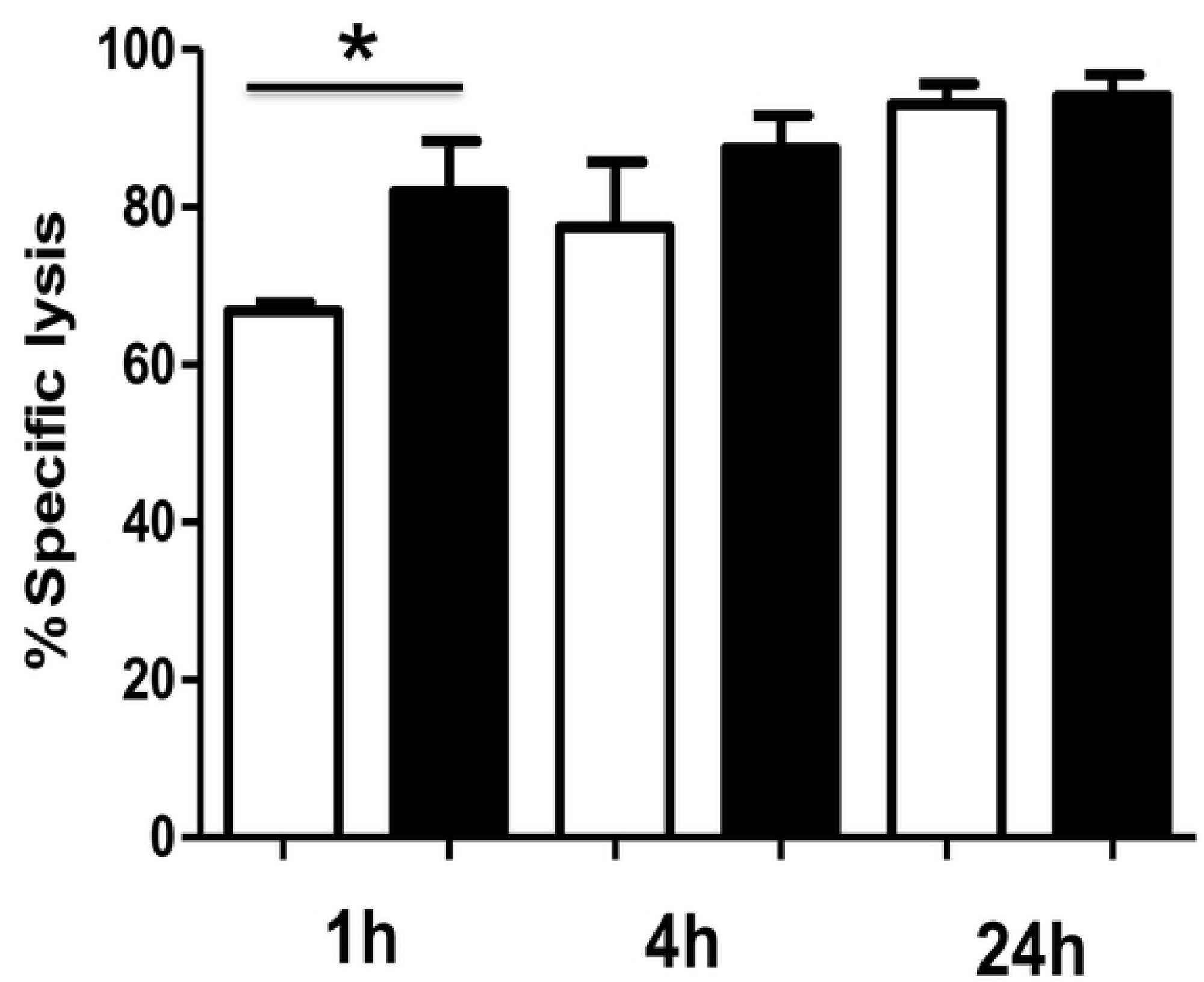

Figure3C 
Day 0
(in vitro)

Day 9

Day 20

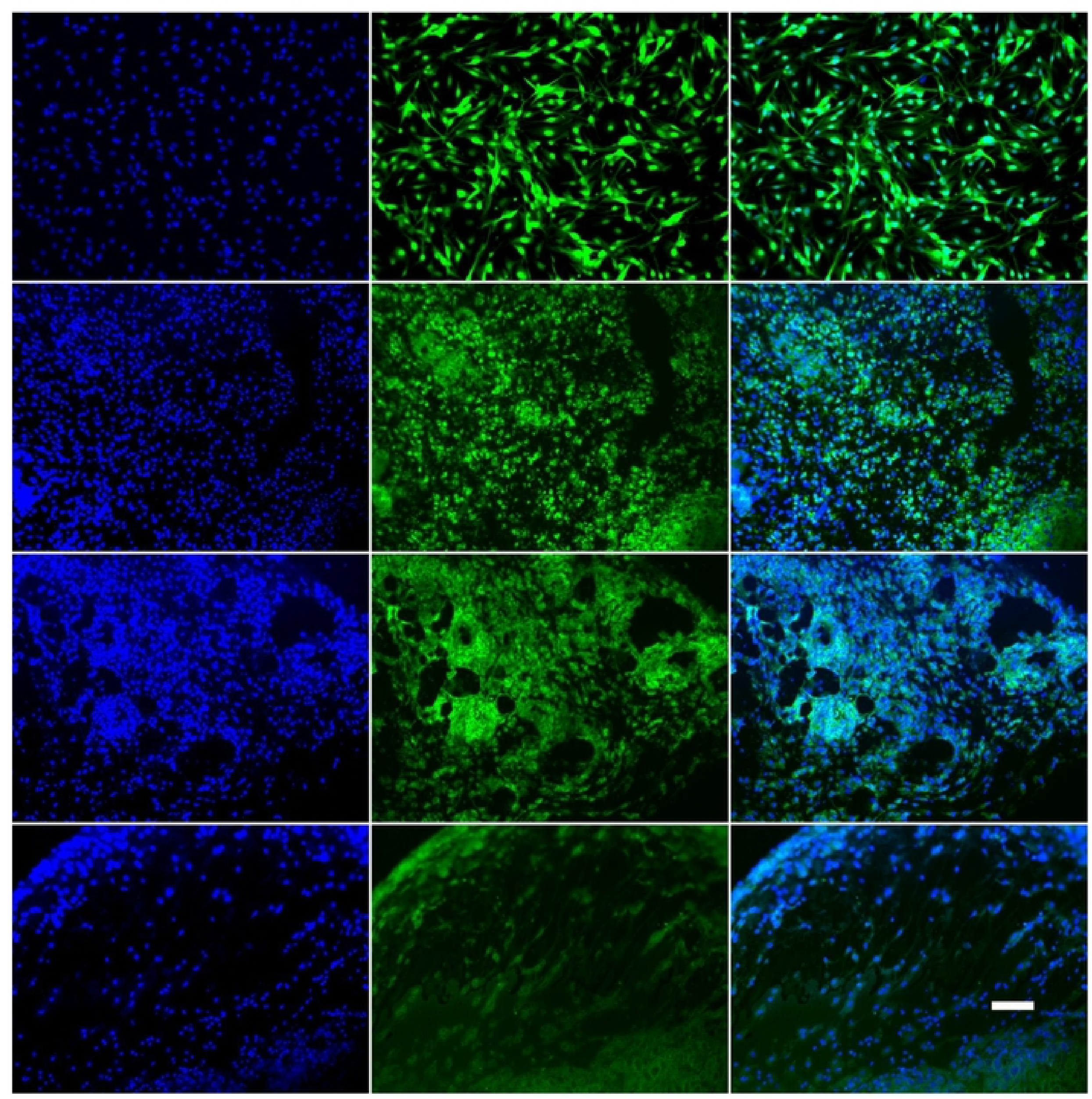

Figure4 

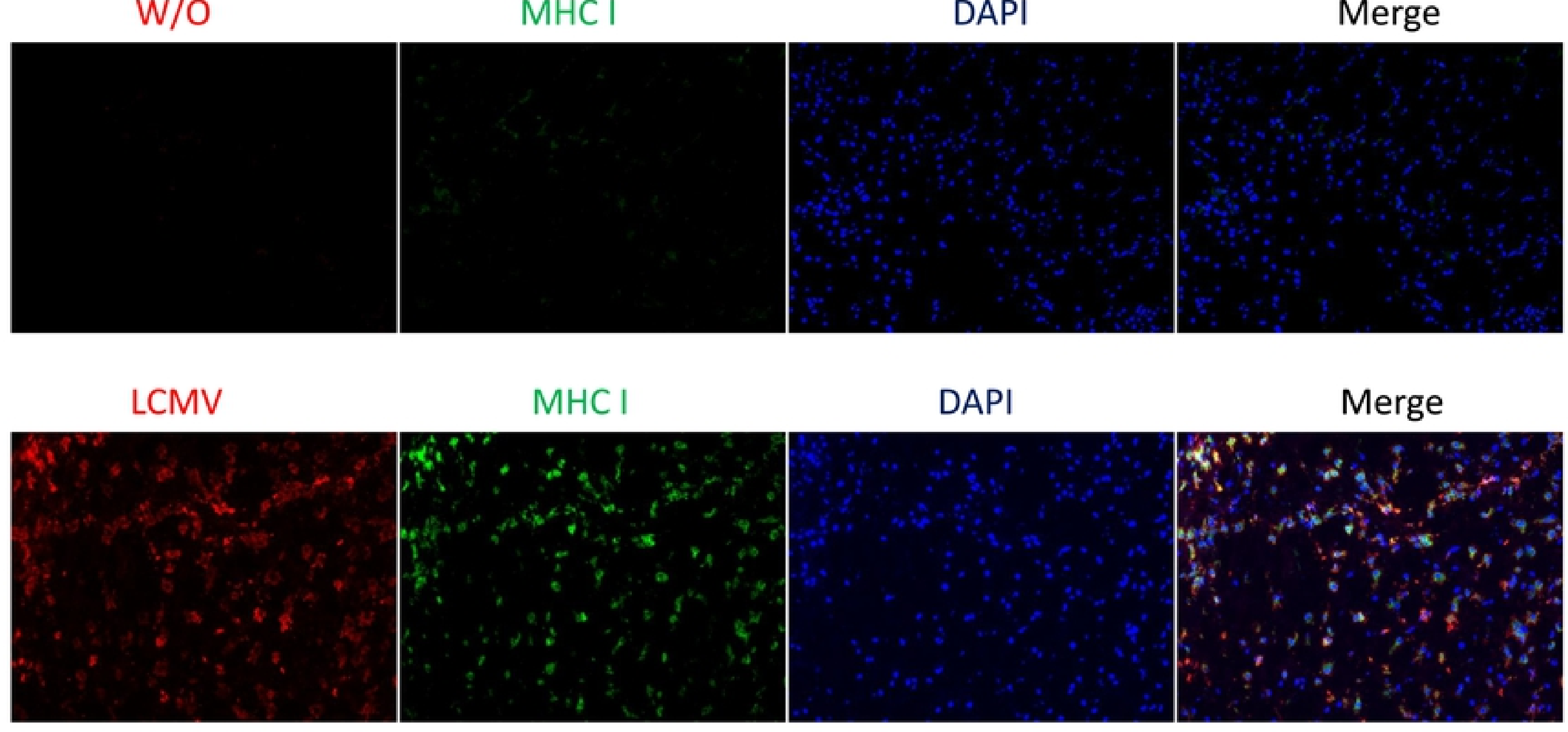

DAPI

Merge

\section{Candid \#1}

$\mathrm{MHCl}$

DAPI

Merge
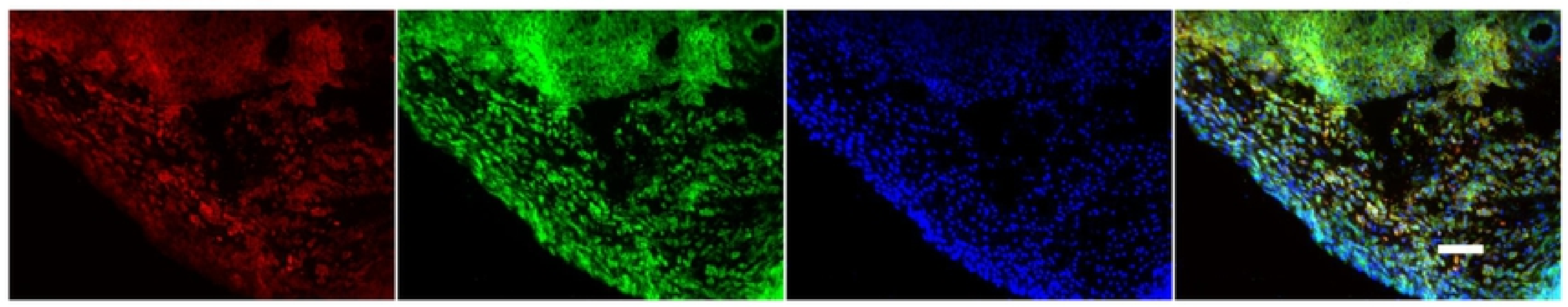

Figure 5A 

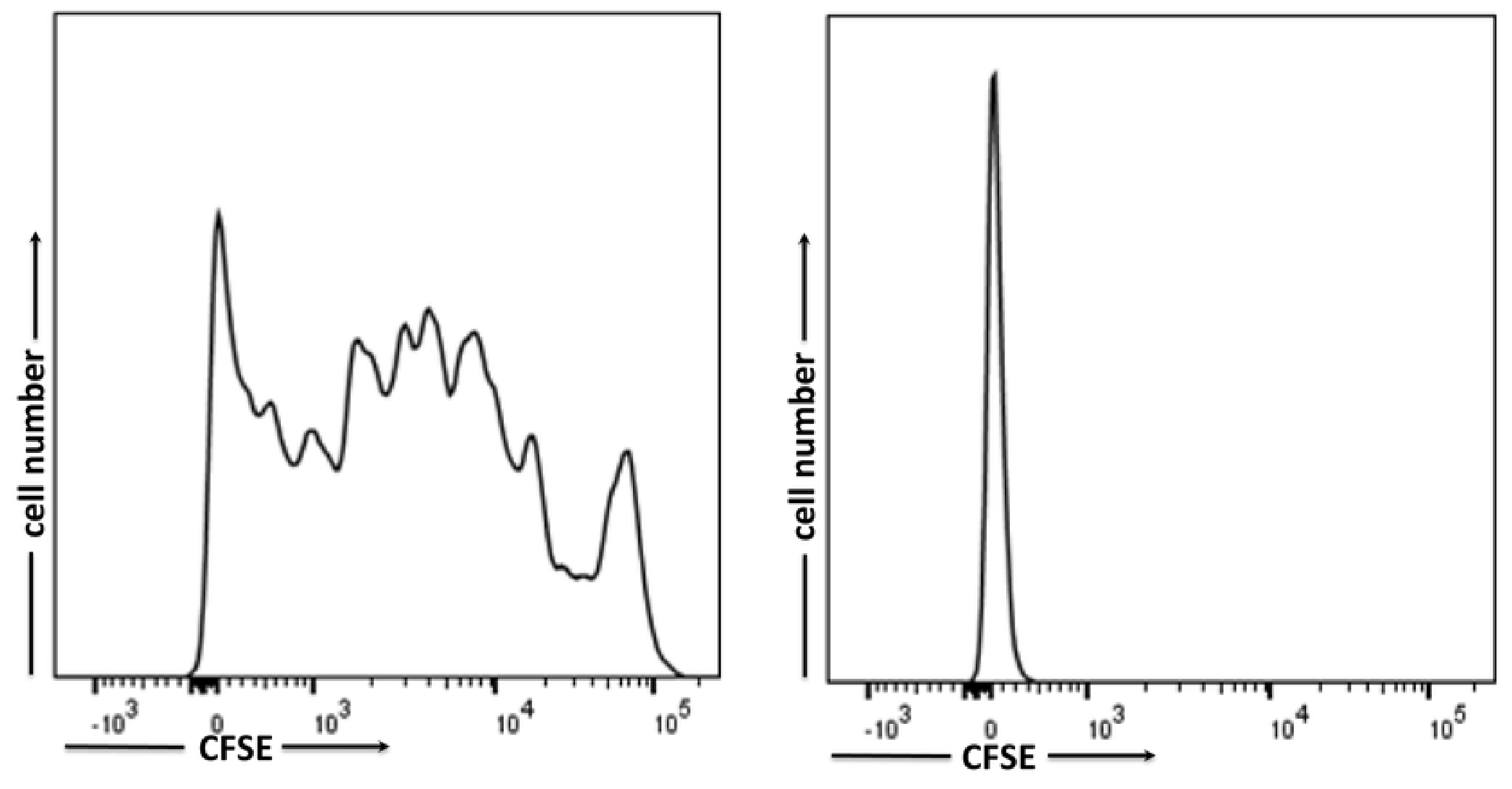

Figure5B 
W/O

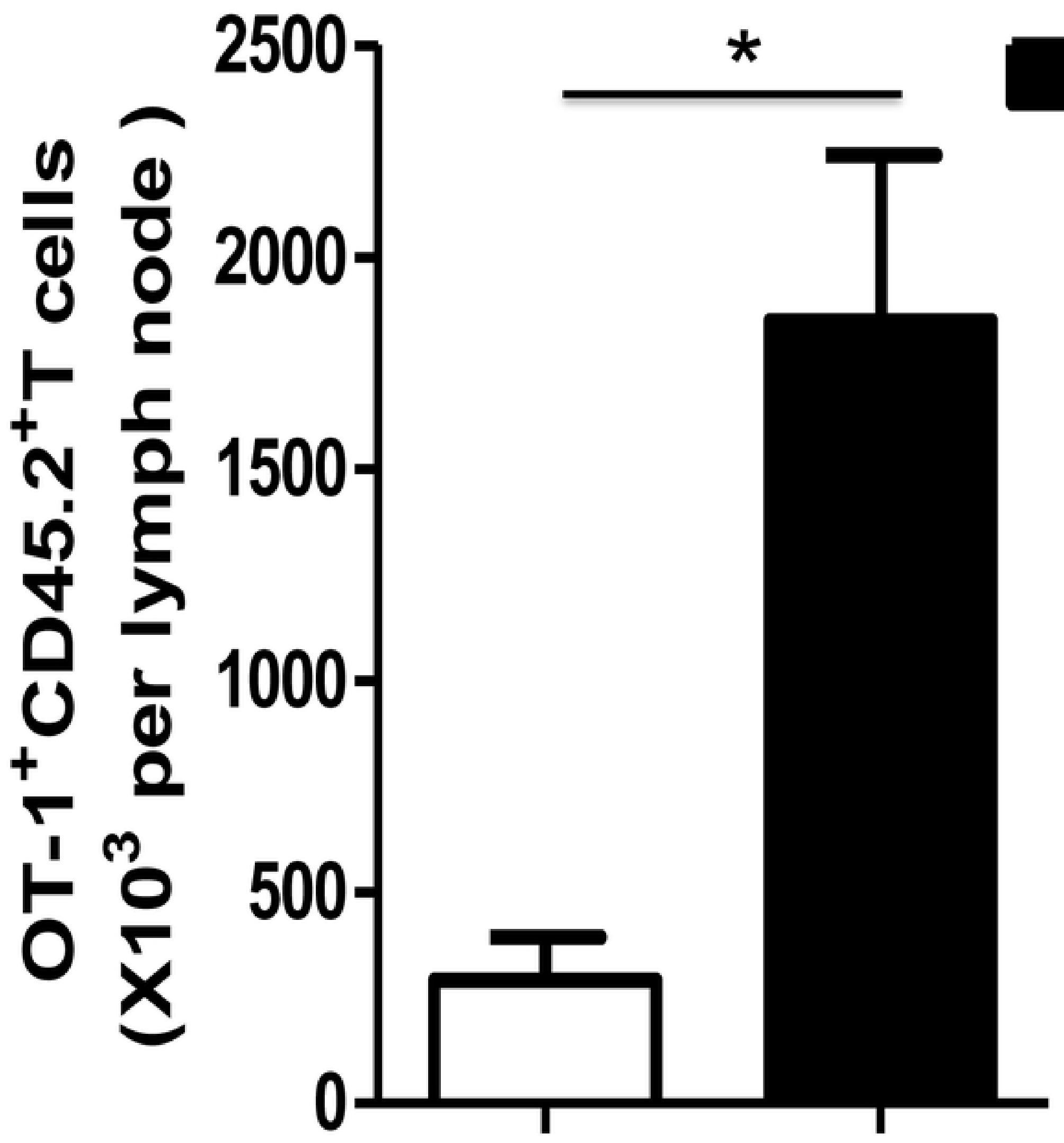

LCMV-WE

Figure5C 


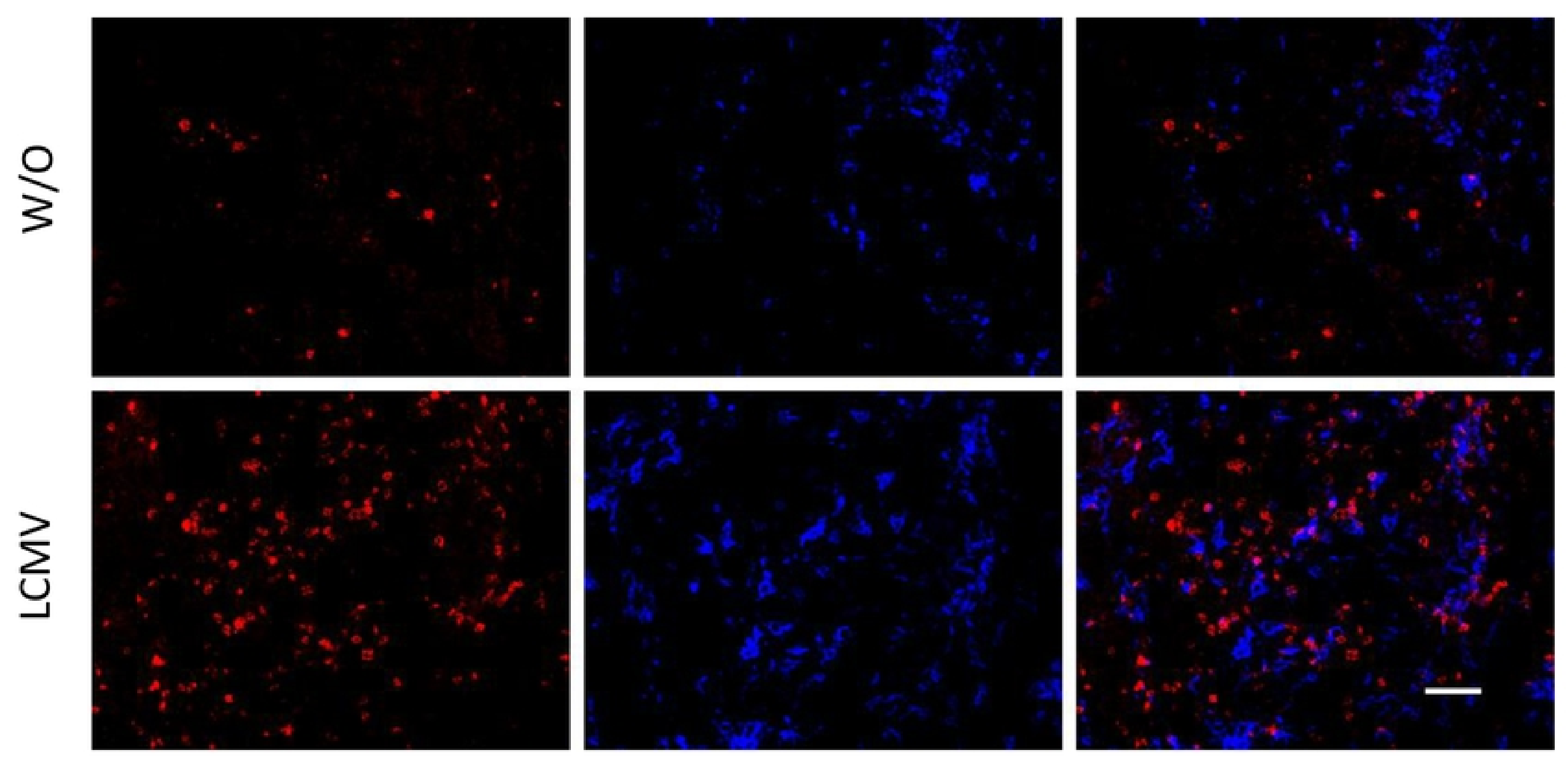

Figure5D 


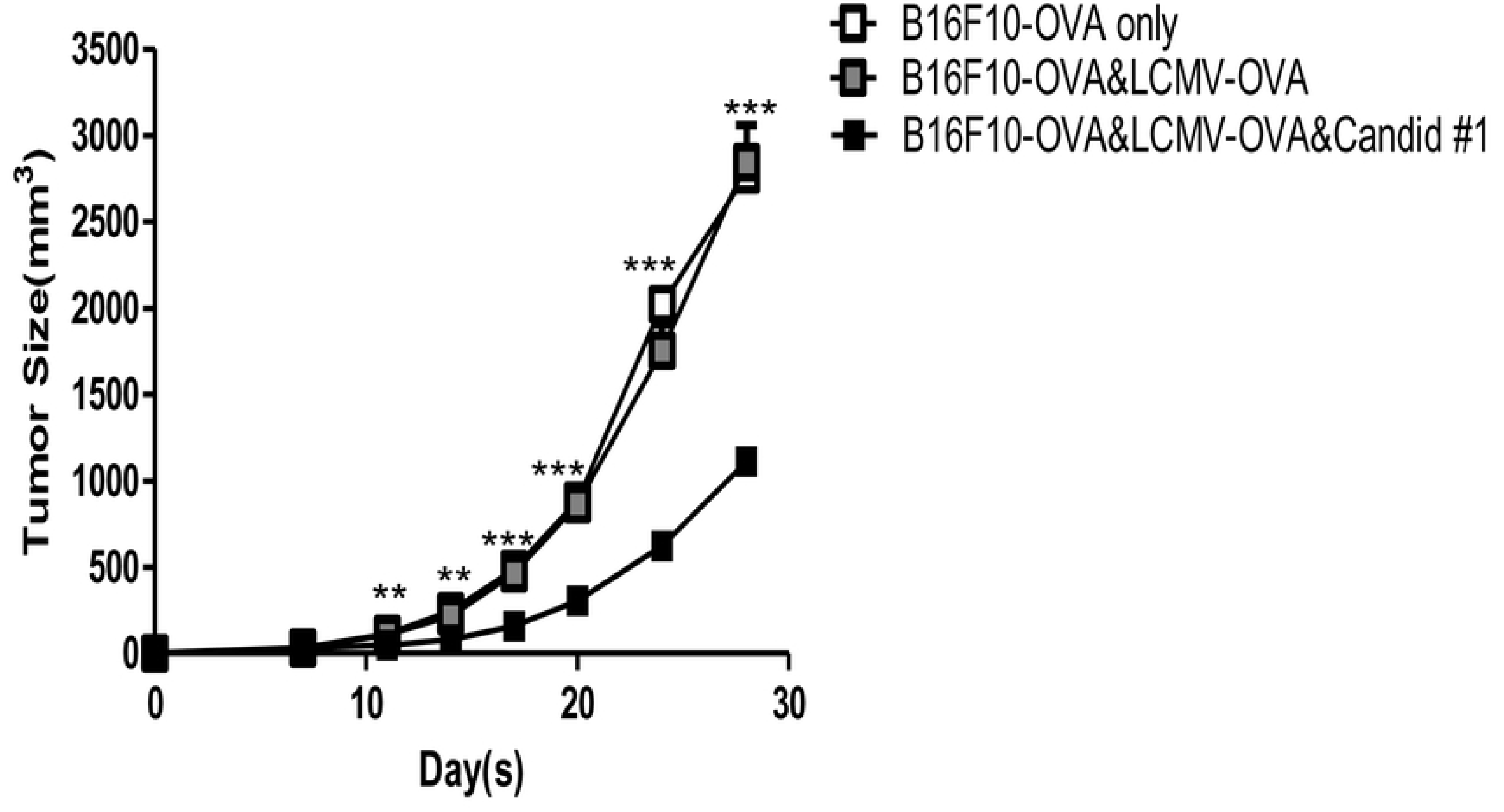

Figure5E 